\title{
Adsorption celebrates 25 years
}

\section{Stefano Brandani ${ }^{1}$}

Published online: 9 December 2019

(c) Springer Science+Business Media, LLC, part of Springer Nature 2019

I would like to thank Professor Shamsuzzaman Farooq for his tireless work over these past 3 years and for developing a number of initiatives that will raise the visibility and impact of our Journal even further. I am very pleased that all four Area Editors (Sofia Calero, Joeri Denayer, Akihiko Matsumoto and Arvind Rajendran) have agreed to continue to serve for at least two more years, ensuring continuity, thus allowing to implement fully the planned activities.

Adsorption was established 25 years ago through the efforts of the members of the International Adsorption Society (IAS), who identified the need to have a journal that covered the full spectrum of research from adsorption fundamentals to adsorption engineering. My first paper in Adsorption was received by Kent Knaebel (the first Editorin-Chief) in December 1994, well before the first issue appeared in March 1995. I have followed the growth of the Journal throughout my career and it is for me truly a great honour to serve the IAS in the role of Editor-in-Chief for its Journal. Adsorption is a fascinating field that allows to see directly how interactions at a molecular level have an effect on how adsorption processes are engineered and, with the rapid growth in novel adsorbent materials that we have experienced over the last 25 years, new phenomena and potential applications are emerging. The field is therefore still expanding and clearly there is the need for a journal dedicated to this area.

Adsorption is meant to serve the community and be one of the archival journals in our field. To do this, I would like to encourage more members of the IAS to be active in contributing to and reviewing papers for the Journal, continuing a tradition that began with its first issue. We obviously welcome high quality contributions from non-members of the IAS and as part of our outreach activities we will establish a new strand with papers dedicated to exploring how to teach adsorption topics, from fundamentals to process applications. This will build on the success of the classes at the recent Fundamentals of Adsorption conferences and at the AIChE Annual meetings, with the aim of providing reference educational material that will allow further longer term growth of our community.

I look forward to working with you and the editorial team at Springer and I take this opportunity to extend my very best wishes to all for the New Year 2020.

Publisher's Note Springer Nature remains neutral with regard to jurisdictional claims in published maps and institutional affiliations.

Stefano Brandani

s.brandani@ed.ac.uk

1 School of Engineering, The University of Edinburgh, Edinburgh, UK 